\title{
MELHORAMENTO DO TRIGO: XV. PRODUTIVIDADE E OUTRAS CARACTERÍSTICAS AGRONOOMICAS DE NOVAS LINHAGENS PARA O ESTADO DE SÃO PAULO ( $\left.{ }^{1}\right)$
}

\author{
CARLOS EDUARDO DE OLIVEIRA CAMARGO $(2,6)$, JOÃO CARLOS FELICIO $(2,6)$, \\ BENEDITO DE CAMARGO BARROS $(3,6)$, JOSÉ GUILHERME DE FREITAS $(2,6)$, \\ ANTONIO WILSON PENTEADO FERREIRA FILHO $\left({ }^{2}\right)$, JAIRO LOPES DE CASTRO $(4,6)$ \\ e JOSÉ CARLOS SABINO $(5,6)$
}

\begin{abstract}
RESUMO
De 1983 a 1985, foram estudadas 22 linhagens de trigo, recém-obtidas, em ensaios instalados no Centro Experimental de Campinas, nas Estaçōes Experimentais de Capāo Bonito e Tietê e na Fazenda Floresta Negra, em Maracal. A produtividade e outras caracterlsticas agronômicas e fitopatológicas foram analisadas em condiçōes de campo e de laboratório. As linhagens IAC-75, IAC-77, IAC-79, IAC-80, IAC-82, IAC-84, IAC-85, IAC87, IAC-88, IAC-89, IAC-90, IAC-91 e IAC-93 apresentaram produções de grãos superiores ao cultivar controle Alondra $S-46$, não diferindo, porém, dos cultivares controles $\mathrm{BH}-1146$ e IAC-18. As linhagens IAC-76, IAC-90, IAC-91, IAC-94 e IAC-96 exibiram porte anāo, diferindo significativamente dos cultivares $\mathrm{BH}-1146$ e IAC-18. Em relação ao oídio, as linhagens IAC-75, IAC-78, IAC-80, IAC-93 e IAC-94 apresentaram o menor grau de infecção; em relação à ferrugem-da-folha em condição de campo, podem-se destacar
\end{abstract}

(1) Com recursos complementares do Acordo do Trigo entre as Cooperativas de Produtores Rurais do Vale do Paranapanema e a Secretaria de Agricultura e Abastecimento, por meio do Instituto Agronômico. Trabalho apresentado na XIV Reuniāo Nacional de Pesquisa de Trigo, Londrina (PR), julho de 1986. Recebido para publicação em 22 de agosto de 1986. pinas (SP).

(2) Seção de Arroz e Cereais de Inverno, Instituto Agronôrnico (IAC), Caixa Postal 28, 13001 Camnas (SP).

(3) Seçăo de Doenças das Piantas Alimentícias Básicas e Olerícolas, Instituto Biológico, 13093 Campi-

(4) Estação Experimental de Capão Bonito, IAC.

(5) Estação Experimental de Tietê, IAC.

(6) Com bolsa de suplementação do CNPq. 
pela boa performance as linhagens IAC-75, IAC-78, IAC-81, IAC-83, IAC-89 e IAC-95. A IAC-93 e o 'BH-1146' mostraram menor ocorrência de doenças de folhas. As linhagens IAC-76 e IAC-96 e o cultivar Alondra S-46 foram considerados resistentes às oito raças testadas do agente de ferrugem-do-colmo em casa de vegetação em estádio de plântula. Nas mesmas condiçōes a linhagem IAC-94 mostrou resistência a seis raças e as linhagens IAC-79, IAC-81, IAC-84, IAC-89, IAC-90 e IAC-95 revelaram-se resistentes a cinco raças. A linhagem IAC-96 foi resistente a três raças de ferrugem-da-folha, em estádio de plåntula. As linhagens IAC-78, IAC-79, IAC-82, IAC-85, IAC-87, IAC-88, IAC-90 e IAC-93 mostraram-se tāo tolerantes ao aluminio quanto os cultivares $\mathrm{BH}-1146$ e IAC-18, e as linhagens IAC-84 e IAC-89, tão sensiveis ao aluminio quanto o cultivar Alondra S-46.

Termos de indexação: trigo, cultivares, linhagens, produtividade, resistência a moléstias; toxicidade de aluminio.

\section{INTRODUÇÃO}

O cultivar Frontana, desenvolvido por Iwar Beckman, na Estação Experimental Fitotécnica da Fronteira, em Bajé, RS, foi posto em distribuição em 1945. Foi largamente cultivado em São Paulo, devido às ótimas qualidades agronômicas e tolerância à acidez do solo, além da resistência à raça 15 de Puccinia graminis $f$. sp. tritici, agente da ferrugerm-do-colmo. Todavia, deixou de ser cultivado pela grande suscetibilidade às raças 11 e 17 daquele patógeno, que surgiram posteriormente (ALCOVER, 1971).

O cultivar BH-1146, obtido por Ildefonso Correia através de seleção do híbrido (PG1 x Fronteira) x Mentana, no Instituto Agronômico de Belo Horizonte, foi recomendado aos agricultores em 1955 (SILVA, 1966), estando até hoje em cultivo no Estado de São Paulo, apesar de ser suscetivel às raças existentes de $P$. graminis f. sp. tritici (FELíCIO et al., 1985, e CAMARGO et al., 1985). É tolerante à acidez do solo (CAMARGO \& OLIVEIRA, 1981), muito precoce e resistente à seca (CAMARGO, 1972).

MENDES (1928) concluiu que um dos principais meios para intensificar a produção de trigo no Brasil seria selecionar cultivares próprios para cada região.

Trabathos desenvolvidos pelo Instituto Agronômico permitiram o lançamento no final da década de 60 e início da década de 70 , dos cultivares com sigla IAC (IAC-1 a IAC-11), dos quais o IAC-5 foi o de maior importância para o Brasil, pois, no final da década de 70 e inicio dos anos 80 , foi o cultivar mais plantado nas diferentes regiōes tritícolas nacionais (ALCOVER, 1969, 1971; CAMARGO, 1972). Atualmente, sua utilização vem diminuindo, principalmente devido ao surgimento de novos cultivares mais produtivos e resistentes aos patógenos causadores das doenças que ocorrem no Estado de São Paulo. 
Trabalhos realizados na década de 70 possibilitaram cultivar variedades de origem mexicana, de porte baixo, resistentes aos patógenos causadores das ferrugens-do-colmo e da-folha em solos de alta fertilidade, sem ocorrência de toxicidade de $\mathrm{Al}^{3+}$ (CAMARGO, 1972; CAMARGO \& ISSA, 1974; FELiCIO et al., 1976). No final da década de 70 e nos anos 80 , novos cultivares de trigo foram lançados para o Estado de São Paulo, provenientes de um trabalho conjunto dos diferentes Institutos de Pesquisa da Coordenadoria da Pesquisa Agropecuária. Esse trabalho permitiu o lançamento de cultivares com sigla IAC com base em ensaios de competição nas diferentes regiöes triticolas paulistas, em solos com e sem alumínio (FELíCIO et al., 1983, 1985; RECOMENDAÇŌES..., 1983, 1984, 1985).

Apesar do trabalho desenvolvido no melhoramento genético do trigo e na experimentação de cultivares e linhagens, há ainda grande demanda no Estado paulista por novos cultivares, mais produtivos, com resistência mais estável aos agentes causais das doenças, adaptados às condiçōes de solo e subsolo ácido, resistentes ao acamamento, com porte baixo e de ciclo precoce.

$O$ presente trabalho teve por objetivo avaliar 22 linhagens, recém-obtidas do programa de melhoramento genético, juntamente com três cultivares comerciais, em diferentes condiçōes de plantio, quanto à produção de grãos, componentes da produção, resistência às doenças e tolerância à toxicidade de aluminio, visando à escolha das mais promissoras para multiplicação e posterior lançamento aos triticultores, ou utiliź́las novamente no programa de cruzamentos visando corrigir possíveis defeitos.

\section{MATERIAL E MÉTODOS}

\subsection{Origem das linhagens e cultivares estudados}

As linhagens estudadas são oriundas de progênies selecionadas e provenientes de cruzamentos realizados no Instituto Agronômico ou introduzidos, envolvendo linhagens e cultivares de diversas procedências.

IAC-75 - Originária da seleção do híbrido F1 928, obtido do cruzamento entre o cultivar Noroeste 66 , proveniente do Centro Internacional de Melhoramento de Milho e Trigo (CIMMYT), México, e a progênie $P$ 18265, originária da Estação Experimental de Capão Bonito.

IAC-76 - Selecionada do híbrido 1196, obtido do cruzamento entre o cultivar IAC-5 e a linhagem IRN 33-70, proveniente do Ensaio Internacional de Ferrugem de Trigo de Primavera de 1970.

IAC-77 e IAC-83 - Oriundas de seleções do híbrido F1 693, que se originou do cruzamento entre o cultivar IAS-51 e a linhagem IRN-597-70.

IAC-78 - Conseguida a partir do híbrido 1002, proveniente do cruzamento entre o cultivar IAC-5 e a linhagem IRN-76-70. 
IAC-79 - Obtida por seleções do híbrido 296, originário do cruzamento entre o cultivar Tobari-66, proveniente do CIMMYT, e o cultivar IAC-5.

IAC-80 e IAC-92 - Selecionadas do híbrido 940, proveniente do cruzamento entre a linhagem E 636 R 71 , originária do Paraguai, e a linhagem P 29256, obtida na Estaçāo Experimental de Capão Bonito. mexicano.

IAC-81 - Obtida por seleçōes do cruzamento entre 'IAC-7’ e 0. 'Norteño',

IAC-82 - Oriunda de seleção do híbrido 1398, obtido pelo cruzamento entre o 'Pitic-62', proveniente do México, e o 'S-15', introduzido da Secretaria da Agricultura do Estado do Rio Grande do Sul.

IAC-84 - Originária do híbrido 336, obtido pelo cruzamento entre a linhagem IRN-618-65 e o cultivar IAS-49, introduzido do IPEAS (Instituto de Pesquisa e Experimentação Agropecuária do Sul), Pelotas, RS.

IAC-85 - Obtida por seleçōes do cruzamento entre os cultivares mexicanos Bajio-67 e Sonora-64.

IAC-86 - Proveniente da seleção de progênies do híbrido 881, que se originou do cruzamento entre a linhagem Pel 21382-66, introduzida do IPEAS, RS, e a IRN-526-63, mexicana.

IAC-87 - Obtida por seleção do híbrido 781 , originado do cruzamento entre a linhagem IRN-112-70 e o cultivar $\mathrm{BH}-1146$.

IAC-88 - Oriunda da seleção do híbrido 804 , proveniente do cruzamento entre as linhagens IRN-325-70 e Pel 5110, introduzida do IPEAS, RS.

IAC-89 - Selecionada a partir do híbrido 995, resultante do cruzamento entre a linhagem IRN-310-70 e o cultivar $\mathrm{BH}-1146$.

IAC-90 e 91 - Obtidas por seleçōes do cruzamento entre a linhagem IRN-641-70 e o cultivar BH-1146.

IAC-93 - Obtida por seleção do híbrido 272, originário do cruzamento entre os cultivares Ciano-67, de origem mexicana, e IAS-51, introduzido do IPEAS, RS.

IAC-94 - Oriunda da seleção do híbrido 815, obtido do cruzamento entre a linhagem Pel 21414-66, introduzida do IPEAS, RS, e o cultivar Noroeste-66, mexicano.

IAC-95 - Setecionada a partir do híbrido 787 , proveniente do cruzamento entre a linhagem IRN-568-70 € o cultivar $\mathrm{BH}-1146$.

IAC-96 - Obtida por seleçöes do cruzamento feito no CIMMYT entre o cultivar Burgas 2, búlgaro, e o híbrido entre os cultivares Sort 12-13, da lugoslávia, e Pavon, mexicano.

Como controles, foram utilizados os seguintes cultivares: $\mathrm{BH}-1146$ e IAC-18, de porte alto, suscetlveis à ferrugem-do-colmo, de ciclo precoce e tolerantes à toxicidade de $\mathrm{Al}^{3+}$, e Alondra S-46, com porte semi-anáo, resistente à 
ferrugem-do-colmo, ciclo médio a tardio e moderadamente sensível à toxicidade de $\mathrm{Al}^{3+}$. A origem dos cultivares utilizados como controle é a seguinte:

BH-1146 - Selecionado no Instituto Agronômico de Minas Gerais, Belo Horizonte, e proveniente do cruzamento 'Ponta Grossa l' x 'Fronteira', híbrido esse que foi cruzado com a variedade Mentana. Fronteira, a primeira variedade de trigo do Brasil, foi obtida pelo cruzamento 'Polissu' x 'Alfredo Chaves'.

IAC-1B - Oriundo da seleção de progênies do hibrido $F$ 1 411, originado do cruzamento entre o 'BH-1146' e o 'S-12', proveniente da Secretaria da Agricultura do Rio Grande do Sul, seguido de três retrocruzamentos para o 'BH-1146'.

Alondra S-46 - Selecionado pelo CIMMYT e introduzido pelo Centro Nacional de Pesquisa de Trigo-EMBRAPA, onde foi resselecionado.

\subsection{Ensaios de campo}

Em 1983 foram instalados três ensaios nos seguintes locais: Fazenda Floresta Negra, município de Maracaí, Estação Experimental de Capāo Bonito e Centro Experimental de Campinas. Em 1984, na Estação Experimental de Tietê e na Fazenda Floresta Negra, e, em 1985, no Centro Experimental de Campinas.

Os experimentos foram compostos de 75 parcelas, sendo utilizado o delineamento estatístico de blocos ao acaso, com três repetições. Cada parcela foi formada de cinco linhas de $3 \mathrm{~m}$ de comprimento espaçadas de $0,20 \mathrm{~m}$. Deixou-se uma separação lateral entre as parcelas de $0,60 \mathrm{~m}$. A semeadura foi feita na base de 80 sementes viáveis por metro de sulco, equivalendo a 1.200 por parcela, com uma área útil de colheita de $3 \mathrm{~m}^{2}$.

Por ocasião da instalação dos ensaios, foram retiradas amostras compostas dos solos dos locais estudados, cujos resultados analíticos $\left({ }^{5}\right)$ são os seguintes:

\begin{tabular}{|c|c|c|c|c|c|c|c|}
\hline \multirow{2}{*}{\multicolumn{2}{|c|}{ Determinaçōes }} & \multicolumn{2}{|c|}{ Maracai } & \multirow{2}{*}{$\begin{array}{c}\text { Capão Bonito } \\
1983\end{array}$} & \multirow{2}{*}{$\begin{array}{l}\text { Tietê } \\
1984\end{array}$} & \multicolumn{2}{|c|}{ Campinas } \\
\hline & & 1983 & 1984 & & & 1983 & 1985 \\
\hline \multicolumn{2}{|c|}{$P$ resina $\left(\mu \mathrm{g} / \mathrm{cm}^{3}\right)$} & 40 & 21 & 25 & 43 & 44 & 33 \\
\hline \multicolumn{2}{|c|}{ M.O. (\%) } & 4,4 & 4,1 & 3,8 & 3,0 & 3,5 & 3,9 \\
\hline \multirow{2}{*}{\multicolumn{2}{|c|}{$\begin{array}{l}\mathrm{pH}\left(\mathrm{CaCl}_{2}\right) \\
\mathrm{K}\left(\mathrm{meq} / 100 \mathrm{~cm}^{3}\right)\end{array}$}} & 5,0 & 5,3 & 4,6 & 5,3 & 4,9 & 5,0 \\
\hline & & 0,17 & 0,18 & 0,15 & 0,60 & 0,27 & 0,27 \\
\hline $\mathrm{Ca}$ & $"$ & 6,8 & 5,0 & 3,1 & 5,3 & 2,6 & 2,3 \\
\hline $\mathrm{Mg}$ & $m$ & 1,7 & 1,4 & 0,7 & 1,3 & 1,0 & 0,8 \\
\hline $\mathrm{H}+\mathrm{Al}$ & 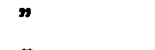 & 3,4 & 2,8 & 5,6 & 2,3 & 4,3 & 4,0 \\
\hline$S$ & $"$ & 8,7 & 6,6 & 4,0 & 7,2 & 3,9 & 3,4 \\
\hline 1 & $"$ & 12,1 & 9,4 & 9,6 & 9,5 & 8,2 & 7,4 \\
\hline \multicolumn{2}{|l|}{$V(\%)$} & 72 & 70 & 42 & 76 & 48 & 46 \\
\hline
\end{tabular}

(5) Análise efetuada pela Seção de Fertilidade do Solo e Nutriçăo de Plantas, Instituto Agronômico. 
Os experimentos conduzidos em Campinas foram irrigados por aspersão. Nas demais localidades não foram irrigados.

Foram coletados os seguintes dados:

Ferrugem-do-colmo e da-folha: Avaliada através de observação geral, em cada parcela, no colmo e nas folhas superiores das plantas, no estádio do inicio de maturação, em condiçōes naturais de infecção, usando-se a escala modificada de Cobb, empregada para avaliação da resistência no Ensaio Internacional de Ferrugem do Trigo (International Spring Wheat Rust Nursery), utilizada por SCHRAM et al. (1974). Esta escala vai de 0 a $100 \%$ de área foliar infectada, complementada pelo tipo de reação: $S=$ suscetivel (uredossoro grande, coalescente, sem necrose e sem clorose); $M S=$ moderadamente suscetivel (uredossoro médio); $M=$ intermediário (diversos tipos de reação); $M R=$ moderadamente resistente (uredossoro pequeno); $\mathbf{R}=$ resistente (uredossoro minúsculo, rodeado de áreas necróticas).

Doenças da folha: Procedeu-se à avaliação de manchas foliares causada por Helminthosporium sp. e Septoria sp. em planta adulta, em condiçōes naturais de infecção, empregando-se uma escala de 0 a $99 \%$ de área infectada, apresentada por METHA (1978), onde 0 é considerado imune; 1 a $5 \%$, resistente; 6 a $25 \%$, moderadamente resistente; 26 a $50 \%$, suscetivel, e 51 a $99 \%$, altamente suscetivel.

Oídio - A avaliação de oídio causado pelo fungo Erysiphe graminis sp. tritici foi feita de maneira idêntica à citada para doenças da folha.

Ciclo da emergência ao florescimento: Por contagens por parcela individual do número de dias da emergência das plântulas ao pleno florescimento.

Ciclo da emergência à maturação: Por contagens por parcela individual do número de dias da emergência das plântulas à maturação fisiológica.

Plantas acamadas: Considerando a porcentagem de plantas acamadas em cada parcela, por avaliação visual próxima à época de maturação.

Altura das plantas: Medida no campo, na época de maturação, a distância, em centímetros, do nivel do solo ao ápice da espiga, excluindo-se as aristas, levando-se em consideraçāo a média de diferentes pontos em cada parcela.

Comprimento da espiga: Considerando o comprimento médio, em centímetros, de vinte espigas tomadas ao acaso em cada parcela, excluindo-se as aristas.

Espiguetas: Computando o número médio de espiguetas de vinte espigas tomadas ao acaso em cada parcela.

Grãos por espiga: Considerando o número médio de grãos contados em vinte espigas colhidas ao acaso em cada parcela.

Grãos por espigueta: Calculando-se pela divisão do número total de grãos de vinte espigas pelo número total de espiguetas das mesmas vinte espigas, coletadas ao acaso em cada parcela. 
Peso de cem grãos: Considerando o peso em gramas de cem grãos tomados ao acaso da produção total de cada parcela.

Produção de grãos: Considerando a produção total de grāos de cada parcela, medida em gramas, a qual foi transformada para quilograma/hectare.

\subsection{Ensaios em condição de casa de vegetação e laboratório}

\subsubsection{Resistência às ferrugens-do-colmo e da-folha}

Remeteram-se as sementes das linhagens e cultivares estudados ao laboratório do Centro Nacional de Pesquisa de Trigo - EMBRAPA, Passo Fundo, RS, para serem identificadas quanto à resistência em estádio de plântula às raças fisiológicas do agente causal da femugem-do-colmo $(G 13, G 15, G 17, G 18$, G19, G20, G21 e G22) e da ferrugem-da-folha (B26, B27 e B29) em casa de vegetação.

Os critérios utilizados nas avaliações encontram-se no quadro 3.

\subsubsection{Tolerância à toxicidade de aluminio}

As linhagens e cultivares foram testados para tolerância a 0,2, 4, 6, 8 e $10 \mathrm{mg} /$ litro de $\mathrm{Al}^{3+}$ em soluçōes nutritivas, conforme método já publicado (CAMARGO \& OLIVEIRA, 1981; CAMARGO et al., 1980, e MOORE et al., 1976).

\section{RESULTADOS E DISCUSSÃO}

As produçōes médias de grãos, transformadas em quilograma/hectare das linhagens e cultivares de trigo estudados de 1983 a 1985, em diferentes regiōes paulistas, encontram-se no quadro 1 . Os resultados da análise estatística dos seis experimentos, analisados separadamente, mostram efeitos altamente significativos para linhagens e cultivares.

Através do teste de Tukey aplicado ao nível de $5 \%$ para a comparação das médias nos tratamentos no ensaio de linhagens e cultivares instalados na Fazenda Floresta Negra, em Maracal, em 1983, em condição de sequeiro, verificou-se que as linhagens IAC-79 e IAC-80 produziram respectivamente 2.274 e $2.210 \mathrm{~kg} / \mathrm{ha}$, porém não diferiram dos cultivares controles $\mathrm{BH}-1146, \mathrm{IAC}-18$ e Alondra S-46 que produziram respectivamente $1.877,1.806$ e $1.828 \mathrm{~kg} / \mathrm{ha}$. No ensaio instalado em 1985, em Maracal, destacaram-se quanto à produção as linhagens IAC-91 e IAC-87, que não diferiram dos cultivares controles. IAC-91, porém, diferiu ao nivel de $5 \%$ das linhagens: IAC-75, IAC-77, IAC-78, IAC-79, IAC-82, IAC83, IAC-85, IAC-92 e IAC-95, e IAC-87 diferiu, ao nivel de 5\%, somente das linhagens: IAC-75, IAC-77, IAC-78, IAC-82, IAC-83 e IAC-85. 
QUADRO 1. Produção média de grãos das linhagens e cultivares de trigo estudados nos ensaios conduzidos na Fazenda Floresta Negra, em Maracal (1983 e 1984), na Estaçāo Experimental de Capão Bonito (1983), na Estaçăo Experimental de Tietê (1984) o no Contro Exporimonlal do Campinas (1983 0 1985)

\begin{tabular}{|c|c|c|c|c|c|c|c|}
\hline Cultivares & $\begin{array}{c}\text { Maracal } \\
1983\end{array}$ & $\begin{array}{c}\text { Capão Bonito } \\
1983\end{array}$ & $\begin{array}{c}\text { Campinas } \\
1983\end{array}$ & $\begin{array}{l}\text { Tietê } \\
1984\end{array}$ & $\begin{array}{c}\text { Maracal } \\
1984\end{array}$ & $\begin{array}{c}\text { Campinas } \\
1985\end{array}$ & Média \\
\hline & & & & $\mathrm{kg} / \mathrm{ha}$ & & & \\
\hline 1. $\mid A C=75$ & 2.073 & 810 & 2.463 & 1.898 & 702 & 2.510 & 1.743 \\
\hline 2. $1 A C-76$ & 2.151 & 422 & 1.301 & 2.087 & 1.323 & 1.640 & 1.487 \\
\hline 3. $\mid A C-77$ & 1.874 & 666 & 1.990 & 2.564 & 1.026 & 1.978 & 1.683 \\
\hline 4. $1 A C-78$ & 1.930 & 799 & 2.012 & 1.354 & 706 & 2.743 & 1.591 \\
\hline 5. $1 \mathrm{AC}-79$ & 2.274 & 1.132 & 1.980 & 1.754 & 1.246 & 2.056 & 1.740 \\
\hline 6. $1 A C-80$ & 2.210 & 955 & 1.828 & 1.154 & 1.278 & 2.543 & 1.661 \\
\hline 7. $\mid A C-81$ & 1.329 & 433 & 1.604 & 1.776 & 1.558 & 1.808 & 1.418 \\
\hline 8. $\mid A C-82$ & 2.130 & 522 & 2.143 & 2.009 & 807 & 2.202 & 1.636 \\
\hline 9. $I A C-83$ & 1.984 & 710 & 2.008 & 1.731 & 687 & 2.361 & 1.580 \\
\hline 10. IAC-84 & 1.916 & 400 & 1.790 & 1.776 & 1.735 & 2.131 & 1.625 \\
\hline 11. $\mid A C-85$ & 1.808 & 500 & 2.258 & 2.065 & 1.112 & 2.261 & 1.667 \\
\hline 12. IAC-86 & 2.111 & 977 & 1.462 & 899 & 1.567 & 2.085 & 1.517 \\
\hline 13. $\mid A C-87$ & 1.674 & 511 & 2,207 & 2.109 & 1.886 & 2.076 & 1.744 \\
\hline 14. IAC-88 & 2.083 & 599 & 2.274 & 2.131 & 1.545 & 2.314 & 1.825 \\
\hline 15. IAC-89 & 1.743 & 688 & 2.476 & 2.742 & 1.339 & 2.030 & 1.836 \\
\hline 16. IAC-90 & 2.020 & 1.033 & 1.331 & 1.332 & 1.503 & 3.090 & 1.718 \\
\hline 17. IAC-91 & 1.544 & 511 & 1.932 & 2.353 & 1.999 & 2.217 & 1.759 \\
\hline 18. $\mid A C-92$ & 2.139 & 277 & 1.450 & 1.421 & 1.180 & 2.871 & 1.556 \\
\hline 19. IAC-93 & 1.972 & 644 & 2.374 & 2.131 & 1.292 & 2.312 & 1.787 \\
\hline 20. $\mid A C-94$ & 1.530 & 444 & 1.863 & 1.732 & 1.472 & 2.530 & 1.595 \\
\hline 21. IAC-95 & 1.663 & 611 & 1.795 & 1.531 & 1.258 & 2.173 & 1.505 \\
\hline 22. IAC-96 & 1.869 & 644 & 1.400 & 1.543 & 1.414 & 1.525 & 1.399 \\
\hline 23. $\mathrm{BH}-1146$ & 1.877 & 633 & 1.738 & 1.909 & 1.763 & 2.054 & 1.662 \\
\hline 24. IAC-18 & 1.806 & 544 & 1.722 & 2.586 & 1.731 & 2.156 & 1.757 \\
\hline 25. Alondra S-46 & 1.828 & 555 & 809 & 588 & 1.529 & 1.874 & 1.197 \\
\hline$F$ & $4,73^{* *}$ & $6,72^{* *}$ & $8,65^{* *}$ & $2,59^{* *}$ & $7,46^{* *}$ & $5,12^{* *}$ & $3,29^{*}$ \\
\hline CV\% & 9,72 & 22,07 & 12,95 & 30,63 & 17,10 & 12,36 & 21,22 \\
\hline d.m.s. & 580 & 443 & 750 & 1.747 & 722 & 861 & 419 \\
\hline
\end{tabular}

*- Significativo ao nivel de $1 \%$.

No ensaio de linhagens plantado em Campinas, em 1983, em condiçāo de irrigação por aspersão, apenas $1 A C-89$, que produziu $2.476 \mathrm{~kg} / \mathrm{ha}$, diferiu significativamente dos cultivares IAC-18 e Alondra S-46 com produçöes de 1.722 e $809 \mathrm{~kg} / \mathrm{ha}$ respectivamente. No ensaio de 1985 , destācaram-se, quanto à prođuçăo de grãos, as linhagens IAC-90, IAC-92 e IAC-78. A primeira diferiu ao nivel de $5 \%$ dos cultivares $\mathrm{BH}-1146, \mathrm{AC}-18$ e Alondra S-46 e as duas restantes apenas do cultivar Alondra S-46.

No ensaio plantado em Capão Bonito, em 1983, as linhagens IAC-79 e IAC-90 obtiveram as maiores produçōes de grãos. IAC-79 diferiu ao nivel de $5 \%$ dos três cultivares controles e a linhagem IAC-90 apenas dos cultivares IAC-18 e Alondra S-46. 
As linhagens IAC-89, IAC-77 e IAC-91 destacaram-se quanto à produção de grãos no ensaio instalado em Tietê, em 1984, porém diferindo somente do 'Alondra S-46'.

Analisando em conjunto os seis ensaios, verificaram-se efeitos altamente significativos para genótipo, ensaio e interação genótipo $x$ ensaio. Pelo teste de Tukey a 5\%, observou-se que IAC-89, IAC-88, IAC-93, IAC-91, IAC-87, IAC-75, IAC-79, IAC-90, IAC-77, IAC-85, IAC-80, IAC-82 e IAC-84 foram os mais produtivos, porém somente diferiram do controle 'Alonidra S-46'.

No quadro 2 encontram-se os maiores graus de infecçāo de ofdio, ferrugem-da-folha e do-colmo e manchas foliares, alcançados pelos cultivares e linhagens, considerando os seis experimentos.

Em 1983, 1984 e 1985, não ocorreram condiçōes naturais favoráveis de infecção do agente causal da ferrugern-do-colmo. Mesmo o cultivar $\mathrm{BH}-1146$, previamente conhecido como altamente suscetivel a essa doença, exibiu no período de estudo um grau máximo de infecção de tS.

Em relação à ferrugem-da-folha, destacaram-se, quanto à resistência em planta adulta, as linhagens IAC-75, IAC-78, IAC-81, IAC-83, IAC-89 e IAC-95, com graus de infecção iguais ou inferiores a 10S. Nessa mesma situação, o 'Alondra S-46', suscetível à ferrugem-da-folha, exibiu um grau de infecção máximo de 40S. As linhagens IAC-78, IAC-81, IAC-83 e IAC-95 apresentaram produções não significativamente diferentes do cultivar Alondra-S-46, porém exibiram menor suscetibilidade à ferrugem-da-folha em condições de campo, podendo ser aproveitadas em cruzamentos no programa de melhoramento.

Em relação ao oídio, destacaram-se, quanto à resistência em planta adulta, as linhagens IAC-75, IAC-78, IAC-80, IAC-93 e IAC-94, com graus de infecção iguais ou inferiores a 30 . Nessa mesma situação, em condições naturais de infeç̧ão, os cultivares IAC-18, BH-1146 e Alondra S-46 exibiram respectivamente 40,60 e 80 como graus máximos de infecção.

A ocorrência de helmintosporiose foi bastante acentukitia : io ensaio plantado em Capão Bonito, em 1983, sendo suscetiveis praticamente todas as linhagens e cultivares. Destes, 'BH-1146' ' 2 'IAC-93' foram os que apresentaram menor intensidade de ataque.

As reaçōes das linhagens e cultivares (estádio de plântula) a Puccinia graminis f. sp. tritici e $P$. recondita, em condiçōes de casa de vegetação, encontram-se no quadro 3. As linhagens IAC-76 e IAC-96 apresentaram-se resistentes às oito raças do agente causal da ferrugem-do-colmo em condiçōes de casa de vegetação. O mesmo comportamento foi observado para 'Alondra-S-46'. A linhagem IAC-94 mostrou resistência a seis raças e as linhagens IAC-79, IAC-81, IAC84, IAC-89, IAC-90 e IAC-95, foram resistentes a cinco raças dessa ferrugem. A linhagem IAC-96 foi resistente às três raças de $P$. recondita, em casa de vegetação, confirmando a sua resistência em condição de campo. 


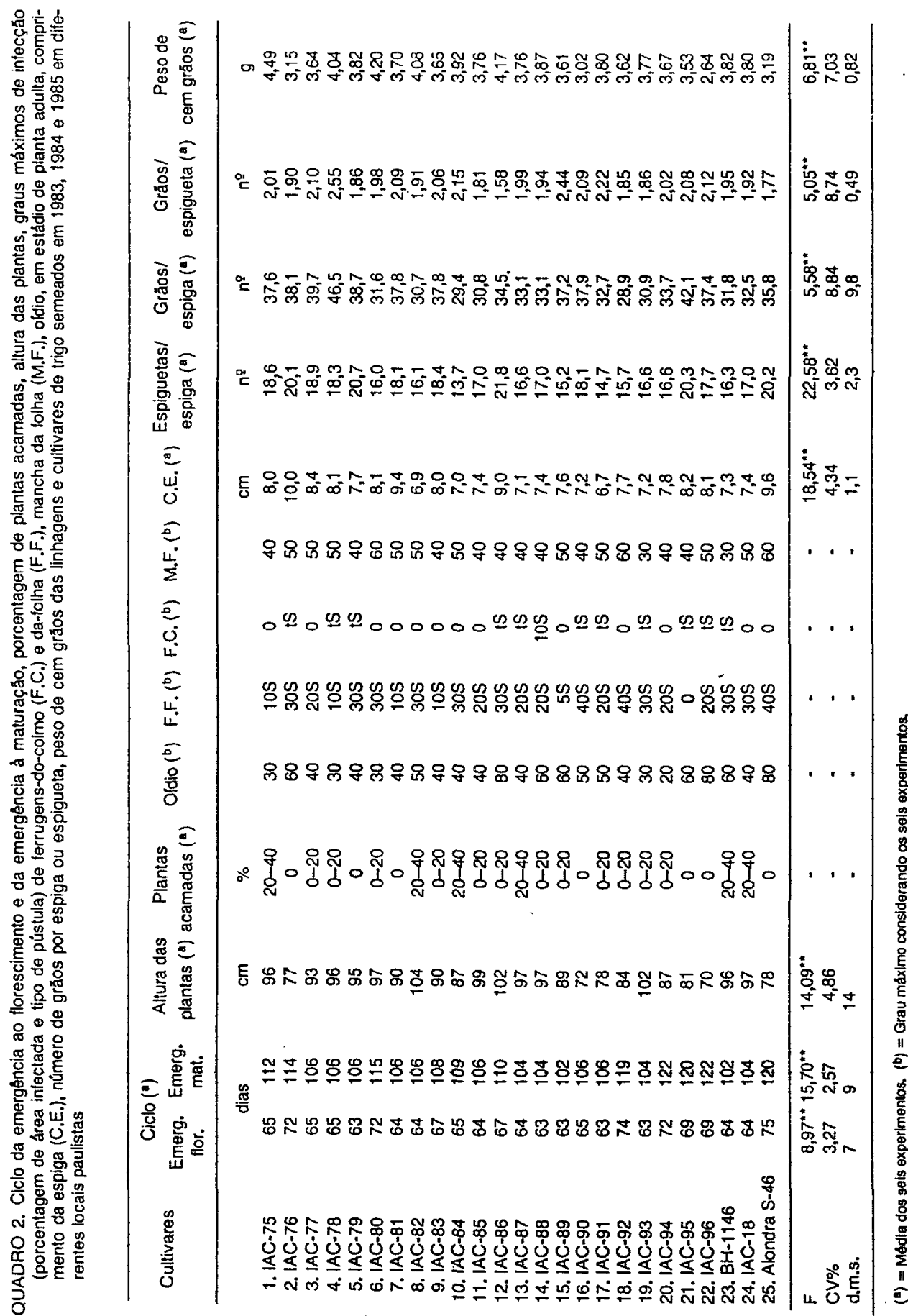


QUADRO 3. Reaçōes das linhagens e cultivares de trigo (estádio de plântula) às raças de Puccinia graminis tritici, agente causal da ferrugem-do-colmo, e de Puccinia recondita, agente causal da ferrugem-da-folha, em condiçōes controladas de casa de vegetação do Centro Nacional de Pesquisas de Trigo - EMBRAPA, Passo Fundo, RS

\begin{tabular}{|c|c|c|c|c|c|c|c|c|c|c|c|}
\hline \multirow[t]{2}{*}{$\begin{array}{l}\text { Cultivares e } \\
\text { linhagens }\end{array}$} & \multicolumn{8}{|c|}{ Raças fisiológicas de Puccinia graminis tritici } & \multicolumn{3}{|c|}{$\begin{array}{l}\text { Raças fisiológicas } \\
\text { de Puccinia recondita }\end{array}$} \\
\hline & G13 & G15 & G17 & G18 & G19 & G20 & G21 & G22 & $\mathrm{B} 26$ & $\mathrm{~B} 27$ & B29 \\
\hline IAC-75 & - & - & - & - & - & - & - & - & - & - & - \\
\hline IAC-76 & 1 & 1 & 0 & 0 & $2-$ & 0 & 0 & $1-$ & 4 & 0 & $0 ; e 2$ \\
\hline IAC-77 & 3 & 4 & $3-$ & $3-$ & 3 & 3 & 3 & - & 4 & - & 3 \\
\hline IAC-78 & - & - & - & - & - & - & - & - & 2 & 0 & 4 \\
\hline IAC-79 & 0 & $1-$ & 0 & 0 & 4 & 3 & 3 & 0 & 4 & 4 & 4 \\
\hline IAC-80 & 3 & $1-$ & 0 & 1 & 4 & 4 & 4 & $1-$ & 4 & 4 & 2 \\
\hline IAC-81 & 2 & 1 & 0 & 0 & 4 & 3 & 3 & $1-$ & 4 & 4 & 4 \\
\hline IAC-82 & 4 & 4 & 0 & $2++$ & 4 & 3 & 2 & 3 & 4 & 3 & 3 \\
\hline IAC-83 & - & - & - & - & - & - & - & - & - & 3 & 2 \\
\hline IAC-84 & 2 & $1-$ & 0 & 0 & $3-$ & 3 & $3-$ & 1 & 4 & 4 & $0 ; e 2$ \\
\hline IAC-85 & - & - & - & - & - & - & - & - & - & - & - \\
\hline IAC-86 & 3 & 4 & 3 & 3 & 4 & 3 & 4 & 4 & 4 & 4 & 3 \\
\hline IAC-87 & 4 & 4 & 4 & 4 & 4 & 4 & 4 & 4 & 4 & 4 & 3 \\
\hline IAC-88 & 4 & 4 & 4 & 4 & 4 & 4 & 4 & 4 & 4 & 4 & 2 \\
\hline IAC-89 & $2+$ & $1-$ & 0 & 0 & 4 & 4 & 4 & 0 & 4 & 4 & 0 \\
\hline IAC-90 & 2 & $1-$ & 0 & 0 & 4 & 3 & $3-$ & $1-$ & 4 & 4 & $0 ; e 3$ \\
\hline $\mid A C-91$ & 3 & 4 & 4 & 4 & 4 & 4 & 4 & 4 & 4 & 4 & 2 \\
\hline IAC-92 & 3 & $1-$ & 0 & 0 & 4 & 4 & 4 & $1-$ & 4 & 4 & 4 \\
\hline IAC-93 & 4 & 4 & 4 & 4 & 4 & 4 & 4 & 3 & 4 & 4 & 3 \\
\hline IAC-94 & $1-$ & 1 & 0 & 0 & 2 & 3 & $3-$ & $1-$ & 4 & 3 & 0 \\
\hline IAC-95 & $2++$ & 0 & 0 & 0 & 4 & 3 & 3 & 0 & 2 & - & 4 \\
\hline IAC-96 & 0 ; & 0 & 0 & 0 & $1-$ & 0 & 0 & 0 & 0 & 0 & 0 \\
\hline $\mathrm{BH}-1146$ & 4 & 4 & 4 & 4 & 4 & 4 & 4 & 4 & 4 & 3 & 4 \\
\hline IAC-18 & 4 & 4 & 2 e 4 & 4 & 4 & 4 & 4 & 4 & 3 & - & $0 ; e 4$ \\
\hline Alondra S-46 & 1 & 1 & 0 & 0 & 1 & 0 & 0 & $1-$ & 3 & 3 & 0 \\
\hline
\end{tabular}

$0 ; 11-22-2+2++=$ resistente. $3--3-33+3++4=$ suscetfvel.

Os cultivares comerciais $\mathrm{BH}-1146$ e IAC-18 foram suscetiveis às oito raças de ferrugem-do-colmo; o primeiro foi suscetivel às três raças e o segundo a duas raças de ferrugem-da-folha no estádio de plântula. Apesar da sua suscetibilidade a várias raças dos patógenos das ferrugens, verificou-se, em condiçōes de 
campo, em 1983, 1984 e 1985, que o grau máximo de infecção não ultrapassou tS para ferrugem-do-colmo e $40 S$ para ferrugem-da-folha, o que decorreu, provavelmente, de condições não favoráveis ao desenvolvimento dos fungos ou de sua incidência tardia.

O ciclo em dias da emergência ao florescimento e da emergência à maturação, a porcentagem de plantas acamadas, a altura da planta, o comprimento da espiga, o número de grãos por espiga e por espigueta, o número de espiguetas e o peso de cem grãos das linhagens e cultivares estudados, considerando a média dos seis ensaios, encontram-se no quadro 2.

As linhagens IAC-77, IAC-78, IAC-79, IAC-81, IAC-82, IAC-83, IAC-84, IAC-85, IAC-86, IAC-87, IAC-88, IAC-89, IAC-90, IAC-91 e IAC-93, foram tão precoces quanto os cultivares comerciais IAC-18 e $\mathrm{BH}-1146$, sendo que as demais linhagens demonstraram um ciclo médio semelhante ao 'Alondra-S-46'.

As linhagens IAC-76, IAC-90, IAC-91, IAC-95 e IAC-96 e o cultivar Alondra-S-46 mostraram plantas significativamente mais baixas que as dos cultivares IAC-18 e BH-1146. Considerando que estes germoplasmas também não exibiram plantas acamadas, estariam, portanto, entre aqueles com potencial de cultivo em condição de irrigação. As linhagens IAC-75, IAC-82, IAC-84 e IAC-87 e os cultivares $\mathrm{BH}-1146$ e $\mathrm{IAC}-18$ apresentaram-se sensiveis ao acamamento, que foi asscriado a um porte de planta de médio para alto. Tais germoplasmas não seriam indicados para condições irrigadas, pois suas produçōes poderiam ser prejudicadas pelo acamamento, na colheita mecânica.

A linhagem IAC-76 foi a que mostrou espigas mais compridas, diferindo estatistic -mente das demais e dos cultivares $\mathrm{BH}-1146$ e IAC-18, com exceção da IAC-81 e IAC-87 e do cultivar Alondra-S-46. A IAC-86 apresentou o maior número de espiguetas por espiga, diferindo das demais e dos cultivares, com exceção da IAC-76, IAC-79 e IAC-95 e do cultivar Alondra-S-46. A linhagem IAC-78 exibiu o maior número de grãos por espiga, não diferindo das linhagens $I A C-75, I A C-76$, IAC-77, IAC-79, IAC-81, IAC-83, IAC-89, IAC-90, IAC-95 e IAC-96. A IAC-78 também mostrou espigas com maior fertilidade, isto é, com maior número de grãos por espigueta, diferindo estatisticamente de todas as linhagens e cultivares, com exceção das linhagens IAC-77, IAC-81, IAC-83, IAC-84, IAC-89, IAC-90, IAC-91, IAC-95 e IAC-96. A linhagem IAC-75 apresentou os grãos mais pesados, diferindo significativamente das linhagens IAC-76, IAC-77, IAC-83, IAC-89, IAC-90, IAC-92, IAC-94 e IAC-95 e do cultivar Alondra-S-46.

O comprimento médio das raizes das 25 linhagens e cultivares de trigo, medido após 72 horas de crescimento nas soluções nutritivas completas, que se seguiram a 48 horas de crescimento nas soluções de tratamento contendo seis diferentes concentraçōes de alumínio, encontram-se no quadro 4.

Considerando $2 \mathrm{mg} /$ litro de $\mathrm{Al}^{3+}$, pode-se verificar que todos os germoplasmas se apresentaram como tolerantes por exibir pelo menos algum crescimento da raiz. 
QUADRO 4. Comprimento médio das rafzes das linhagens e cultivares de trigo medido após 72 horas de crescimento na solução nutritiva completa, que se seguiram a pré-crescimento na solução de tratamento contendo seis diferentes concentraçōes de $\mathrm{Al}^{3+}$

\begin{tabular}{|c|c|c|c|c|c|c|}
\hline \multirow{2}{*}{ Cultivares } & \multicolumn{6}{|c|}{ Concentração de aluminio (mg/l) } \\
\hline & 0 & 2 & 4 & 6 & 8 & 10 \\
\hline 1. $\mid A C-75$ & 46,7 & 22,5 & 39,3 & 31,2 & 2,7 & 0,0 \\
\hline 2. $1 \mathrm{AC}-76$ & 75,3 & 32,4 & 15,7 & 0,3 & 0,0 & 0,0 \\
\hline 3. $1 A C-77$ & 21,6 & 31,4 & 17,0 & 10,0 & 3,8 & 0,0 \\
\hline 4. $\mid A C-78$ & 58,9 & 44,5 & 45,4 & 38,7 & 27,0 & 23,1 \\
\hline 5. IAC-79 & 57,2 & 47,2 & 30,5 & 23,0 & 5,7 & 6,7 \\
\hline 6. IAC-80 & 54,9 & 37,3 & 33,4 & 13,8 & 2,8 & 0,0 \\
\hline 7. IAC-81 & 53,3 & 25,7 & 28,8 & 16,7 & 11,7 & 0,0 \\
\hline 8. IAC-82 & 59,0 & 44,3 & 36,9 & 29,7 & 11,9 & 10,8 \\
\hline 9. $\mid A C-83$ & 35,6 & 35,1 & 33,3 & 27,7 & 1,5 & 0,0 \\
\hline 10. IAC-84 & 78,8 & 0,9 & 0,0 & 0,0 & 0,0 & 0,0 \\
\hline 11. IAC-85 & 86,0 & 67,2 & 61,4 & 48,8 & 31,3 & 22,2 \\
\hline 12. IAC-86 & 47,9 & 36,7 & 27,1 & 7,0 & 0,0 & 0,0 \\
\hline 13. IAC-87 & 84,6 & 64,3 & 54,0 & 43,4 & 22,5 & 21,9 \\
\hline 14. IAC-88 & 95,6 & 68,4 & 60,2 & 49,5 & 30,6 & 19,0 \\
\hline 15. IAC-89 & 60,0 & 3,7 & 0,0 & 0,0 & 0,0 & 0,0 \\
\hline 16. IAC-90 & 67,6 & 54,3 & 45,5 & 30,4 & 12,7 & 0,6 \\
\hline 17. IAC-91 & 50,1 & 37,6 & 42,2 & 24,8 & 4,3 & 0,0 \\
\hline 18. IAC-92 & 62,8 & 38,5 & 28,8 & 17,8 & 6,6 & 0,0 \\
\hline 19. IAC-93 & 88,8 & 59,3 & 54,0 & 39,7 & 22,0 & 22,6 \\
\hline 20. IAC-94 & 77,2 & 37,8 & 30,6 & 4,8 & 1,0 & 0,0 \\
\hline 21. IAC-95 & 50,7 & 39,4 & 31,2 & 27,2 & 3,0 & 0,0 \\
\hline 22. $1 A C-96$ & 66,9 & 40,1 & 31,7 & 9,6 & 1,9 & 0,0 \\
\hline 23. $\mathrm{BH}-1146$ & 81,3 & 68,4 & 51,8 & 45,8 & 28,5 & 21,4 \\
\hline 24. IAC-18 & 87,7 & 70,5 & 62,2 & 39,6 & 28,5 & 18,9 \\
\hline 25. Alondra S-46 & 50,7 & 21,0 & 0,0 & 0,0 & 0,0 & 0,0 \\
\hline
\end{tabular}

As linhagens IAC-84 e IAC-89 e o cultivar Alondra S-46 foram tolerantes a $2 \mathrm{mg} /$ litro de $\mathrm{Al}^{3+}$ na solução tratamento, porém exibiram sensibilidade quando se empregaram soluções com 4 e $6 \mathrm{mg} /$ litro de $\mathrm{Al}^{3+}$, sendo, portanto, consideradas moderadamente sensiveis. 
As linhagens IAC-75, IAC-76, IAC-77, IAC-80, IAC-81, IAC-83, IAC-84, IAC-86, IAC-89, IAC-91, IAC-92, IAC-94, IAC-95 e IAC-96, foram tolerantes a $6 \mathrm{mg} / \mathrm{litro}$ de $\mathrm{Al}^{3+}$, porém demonstraram sensibilidade à presença de $10 \mathrm{mg} / \mathrm{litro}$ de $\mathrm{Al}^{3+}$ nas soluçōes de tratamento. Estes germoplasmas foram considerados moderadamente tolerantes.

Os cultivares $\mathrm{BH}-1146$ e IAC-18, bem como as linhagens IAC-78, IAC79, IAC-82, IAC-85, IAC-87, IAC-88, IAC-90 e IAC-93, apresentaram-se como tolerantes mesmo quando se adicionaram $10 \mathrm{mg} / \mathrm{litro}$ de $A \mathrm{l}^{3+}$ nas soluçōes de tratamento.

\section{CONCLUSÖES}

1) As linhagens IAC-75, IAC-77, IAC-79, IAC-80, IAC-82, IAC-84, IAC-85, IAC-87, IAC-88, IAC-89, IAC-90, IAC-91 e IAC-93 apresentaram produçōes de grãos superiores ao cultivar controle Alondra S-46, porém não diferiram dos cultivares controles $\mathrm{BH}-1146$ e IAC-18. Todas elas exibiram ciclo precoce, exceto IAC75 e IAC-80; tolerância à toxicidade de $\left.A\right|^{3+}$, exceto IAC-89, IAC-91, IAC-75, IAC-77, IAC-80 e IAC-84. As linhagens IAC-91 e IAC-90 mostraram porte baixo a médio; IAC-89 e IAC-75 foram resistentes à ferrugem-da-folha, e IAC-93, IAC-75 e IAC-80 apresentaram resistência ao oldio.

2) As linhagens IAC-76 e IAC-96 e o cultivar Alondra S-46 foram considerados resistentes às oito raças testadas do agente de ferrugem-do-colmo em casa de vegetação, em estádio de plântula. Nas mesmas condiçōes, as linhagens IAC-79, IAC-81, IAC-89, IAC-90, IAC-94 e IAC-95 foram resistentes a cinco raças.

3) Em casa de vegetação, a linhagem IAC-96 foi resistente às três raças do agente de ferrugem-da-folha. Em condição natural de infecção em estádio de planta adulta, as linhagens IAC-75, IAC-78, IAC-81, IAC-83, IAC-89 e IAC-95 apresentaram-se com graus de infecção igual ou inferior a $10 S$.

4) Em condição de infeç̧ão natural, as linhagens IAC-75, IAC-78, IAC-80, IAC-93 e IAC-94 apresentaram-se com menor grau de infecção do agente causal de ofdio.

5) As tinhagens IAC-76, IAC-90, IAC-91, |AC-95 e IAC-96 e o cultivar Alondra $\mathrm{S}-46$ mostraram plantas significativamente mais baixas que as dos cultivares IAC-18 e BH-1146.

6) As linhagens IAC-84 e IAC-89 e o cultivar Alondra S-46 foram moderadamente sensiveis à toxicidade de $\left.A\right|^{3+}$. IAC-75, IAC-76, IAC-77, IAC-80, IAC81, IAC-83, IAC-84, IAC-86, IAC-89, IAC-91, IAC-92, IAC-94, IAC-95 e IAC-96 foram moderadamente tolerantes e os cultivares $\mathrm{BH}-1146$ e IAC-18 e as linhagens IAC-78, IAC-79, IAC-82, IAC-85, IAC-87, IAC-88, IAC-90 e IAC-93, tolerantes. 


\title{
SUMMARY
}

\author{
WHEAT BREEDING: XV. GRAIN YIELD \\ AND OTHER AGRONOMIC CHARACTERISTICS OF NEW \\ INBREED LINES FOR THE STATE OF SÃO PAULO, BRAZIL
}

Twenty two inbred lines obtained at the Instituto Agronômico from the wheat breeding program plus the cultivars $\mathrm{BH}-1146, \mathrm{AC}-18$ and Alondra S-46 were evaluated in field experiments carried out at Campinas Experimental Center, Tietê and Capão Bonito Experimental Stations and at Floresta Negra Farm, Maracal during the years of 1983, 1984 and 1985. Grain yield, plant height, number of days from emergence to flowering period and from emergence to maturation, percentage of lodging, head length, number of grain per spike and per spikelet, number of spikelets, weight of 100 grains, resistance to powdery mildew, and to stem and leaf rusts were evaluated under field conditions. Tests of resistance to stem and leaf rusts and to aluminum tolerance were also made, respectively, in greenhouse and in laboratory. The lines IAC-75, IAC-77, IAC-79, IAC-80, IAC-82, IAC-84, IAC-85, IAC-87, IAC88, IAC-89, IAC-90, IAC-91 and IAC-93 showed superior productivity. They differed from the 'Alondra S-46' but it was not found significant differences among these lines and the control cultivars $B H-1146$ and $I A C-18$. In relation to powdery mildew, the lines IAC-75, IAC-78, IAC-80, IAC-93 and IAC-94 showed good resistance under field conditions. The lines IAC-76 and IAC-96 and the cultivar Alondra S-46 were resistant at seedling stage to eight races of the causal agent of the stem rust, under greenhouse conditions, 'IAC-94' was resistant to six races and 'IAC-79', 'IAC-81', 'IAC-84', 'IAC-89', 'IAC-90', and ' $\mathrm{ACC}-95^{\text {' }}$ were resistant to five races. In relation to leaf rust the line IAC-96 showed high resistance under natural infection out in the field and presented resistance to three races of this rust disease at the seedling stage, under greenhouse conditions. The lines IAC-76, IAC-90, IAC-91, IAC-94, IAC-96 and the cultivar Alondra S-46 exhibited the semi-dwarf type when compared to the tall cultivars $\mathrm{BH}-1146$ and IAC-18. The lines IAC-78, IAC-79, IAC-82, IAC-85, IAC-87, IAC-88, IAC-90 and IAC-93 as well as 'BH1146 ' and 'IAC-18' were tolerant to the presence of $10 \mathrm{mg} / \mathrm{l}$ of $\mathrm{Al}^{3}+$ in the nutrient solution.

Index terms: wheat, cultivars, lines, grain yield, disease resistance, aluminum toxicity.

\section{REFERÊNCIAS BIBLIOGRÁFICAS}

ALCOVER, M. Melhoramento de variedades de trigo em São Paulo. Campinas, Coordenadoria de Assistência Técnica Integral, 1971. 26 fls.

- Resultados experimentais com trigo na Estação Experimental de Capão Bonito do Instituto Agronômico de Campinas, Estado de São Paulo. In: REUNIĀO ANUAL CONJUNTA DE PESQUISA DE TRIGO, 1., Pelotas, 1969. Pelotas, Instituto de Pesquisas e Experimentação Agropecuária do Sul, 1969. 10p. (Mimeografado) 
CAMARGO, C.E.O. Estudos de variedades de trigo para o Estado de São Paulo. Piracicaba, Escola Superior de Agricultura "Luiz de Queiroz", 1972. 102p. Tese (Doutoramento)

; FELÍCIO, J.C.; FREITAS, J.G.; BARROS, B.C.; CASTRO, J.L. \& SABINO, J.C. Melhoramento do trigo. XII. Comportamento de novas linhagens e cultivares no Estado de São Paulo. Bragantia, Campinas, 44(2):669-685, 1985.

\& ISSA, E. Estudo comparativo de cultivares de trigo em Latossolo Roxo no Vale do Paranapanema. Bragantia, Campinas, 33:75-86, 1974.

; KRONSTAD, W.E. \& METZGER, R.J. Parent-progeny regression estimates and associations of height level with aluminum toxicity and grain yield in wheat. Crop Science, 20:355-358, 1980.

\& OLIVEIRA, O.F. Toleråncia de cultivares de trigo a diferentes níveis de alumínio em soluçāo nutritiva e no solo. Brägantia, Campinas, 40:21-31, 1981.

FELÍCIO, J.C.; BARROS, B.C.; CAMARGO, C.E.O. \& BÄR, W.H. Maracal (IAC-170 e Xavantes (IAC-18): cultivares de trigo para o Estado de São Paulo. Bragantia, Campinas, 42:15-25, 1983.

-; CAMARGO, C.E.O. \& BARROS, B.C. Estudo comparativo de cultivares de trigo em Latossolo Roxo no Estado de São Paulo em 1974. Bragantia, Campinas, 35:147-154, 1976.

— trigo para o Estado de São Paulo. Bragantia, Campinas, 44(1):115-128, 1985.

MEHTA, Y.R. Doenças do trigo e seu controle. São Paulo, Ceres, 1978. 190p.

MENDES, C.T. O problema do trigo. São Paulo, Secretaria da Agricultura, Indústria e Comércio do Estado de São Paulo, 1928. 66p.

MOORE, D.P.; KRONSTAD, W.E. \& METZGER, R.J. Screening wheai for aluminum tolerance. In: WORKSHOP ON PLANT ADAPTATIONS TO MINERAL STRESS IN PROBLEM SOILS, Beltsville, Maryland, 1976, edited by Madison J. Wright. Proceedings. Ithaca, Cornell University, 1976. p.287-295.

RECOMENDAÇŌES de cultivares de trigo para plantio nas diferentes regiōes triticolas do Estado de São Paulo. In: SÃO PAULO. Secretaria da Agricultura e Abastecimento. Relatório do Acordo entre a S.A.A., através do Instituto Agronómico e as Cooperativas de Produtores Rurais do Vale do Paranapanema. Campinas, 1983. p.200-203.

RECOMENDAÇŌES de cultivares de trigo para plantio nas diferentes regiōes tritfcolas do Estado de São Paulo. In: SĀO PAULO. Secretaria da Agricultura e Abastecimento. Relatório do Acordo entre a S.A.A., através do Instituto Agronômico e as Cooperativas de Produtores Rurais do Vale do Paranapanema. Campinas, 1984. p.219-222.

RECOMENDAÇŌES de cultivares de trigo para plantio nas diferentes regiōes triticolas do Estado de São Paulo. In: SĀO PAULO. Secretaria da Agricultura e Abastecimento. Relatório do Acordo entre a S.A.A., através do Instituto Agronómico e as Cooperativas de Produtores Rurais do Vale do Paranapanema. Campinas, 1985. p.242-245.

SCHRAM, W.; FULCO, W.S.; SOARES, M.H.G. \& ALMEIDA, A.M.P. Resistência de cultivares de trigo em experimentação ou cultivo no Rio Grande do Sul às principais doenças fúngicas. Agronomia Sulriograndense, Porto Alegre, 10:31-39, 1974.

SILVA, A.R. Melhoramento de variedades de trigo destinadas a diferentes regiōes do Brasil. Rio de Janeiro, Ministério da Agricultura, Serviço de informação Agrícola, 1966. 82p. (Estudos técnicos, 33) 